\title{
Process design based on FE simulations and experiments of forging a complex-shaped magnesium alloy adaptor
}

\author{
Wenchen $\mathrm{Xu}^{*}$, Chuan Yang, Debin Shan, and Bin Guo \\ Schools of Materials Science and Engineering, Harbin Institute of Technology, Harbin 150001, P.R. China
}

Received 18 April 2017 / Accepted 1 June 2017

\begin{abstract}
High-strength magnesium alloys show great potentials for aviation and aerospace applications due to their special strength and low density, but these are difficult to form because of the poor formability and narrow, feasible forging-temperature ranges. Isothermal forging is an effective method to manufacture complex-shaped components with a magnesium alloy, in which the avoidance of forming defects and improvement of mechanical properties are of great concern. The process design of complex-shaped MB26 magnesium alloy adaptor based on finite element (FE) simulations and forging experiments was conducted in this study. A combined female-die was used in order to remove the adaptor forging with three branches. Different forming schemes were analyzed and compared through finite element method (FEM) simulations and forging experiments. The results showed that, compared with a one-step forging process, two-steps forging was more appropriate for forming the adaptor, which not only improved the filling quality but also reduced the forging load. In addition, the aging treatment after hot forging could only slightly improve the mechanical properties of the MB26 adaptor forging, because of the minor addition of rare earth (RE) elements.
\end{abstract}

Key words: Magnesium alloy adaptor, Forging process design, FE simulation, Forging experiments

\section{Introduction}

Magnesium alloys are light-weight and high-strength structural materials, which have great potentials in the application of aviation, aerospace and automobile industries [1]. However, magnesium alloys exhibit low workability due to the limited number of slip systems associated with hexagonal close packaged (HCP) crystal structure. Currently, most of magnesium alloy components are used in the as-cast condition, which are hard to meet high performance service requirements [2]. Compared to the castings, magnesium alloys subject to plastic deformation exhibit improved strength and ductility, loading bearing capacity, shock resistance ability, etc. Therefore, hot precision forging of magnesium alloys are garnering increasing attention in recent years $[3,4]$. In particular, isothermal precision forging is extensively utilized to manufacture complex-shaped structural components of hard-to-deform metals, such as magnesium, aluminium and titanium alloys [5-8]. For instance, Yan et al. successfully produced magnesium alloy upper housing of helicopter through isothermal precision forging process [9]. A. Dziubińska et al. adopted semi-open die forging to form AZ31 magnesium aircraft brackets [10]. Rabori et al. studied on the microstructure and superior

*e-mail: xuwc_76@hit.edu.cn mechanical properties of a multi-axially forged WE magnesium alloy [11]. He et al. performed the simulation and experimental research on isothermal forging of large AZ80 magnesium alloy support beam [12]. However, the isothermal forging process of complex-shaped component is not easy to determine since magnesium alloys have narrow forging temperature range and poor deformability.

In the present study, the forging process of a MB26 magnesium adaptor with three branches is designed with combined female die. Different forging schemes are compared and the defect mechanisms are analyzed through finite element (FE) simulation and process experiment, based on which the two step forging process was determined to form the adaptor component. Besides, the microstructure and mechanical properties of the MB26 adaptor are analyzed during isothermal forging and post-forging heat treatment.

\section{Material and forging schemes}

\subsection{Materials and target component}

The material used in the present investigation is MB26 magnesium alloy, belonging to $\mathrm{Mg}-\mathrm{Zn}-\mathrm{Zr}$ alloy with minor addition of rare element $\mathrm{Y}$. The chemical composition of the 
Table 1. Chemical composition of MB26 magnesium alloy (wt.\%).

\begin{tabular}{lcccccccr}
\hline $\mathrm{Zn}$ & $\mathrm{Zr}$ & $\mathrm{Mn}$ & $\mathrm{Al}$ & $\mathrm{Fe}$ & $\mathrm{Si}$ & $\mathrm{Cu}$ & $\mathrm{Y}$ & $\mathrm{Mg}$ \\
\hline 6.33 & 0.79 & 0.01 & 0.004 & 0.003 & 0.002 & 0.002 & 0.93 & Balance \\
\hline
\end{tabular}
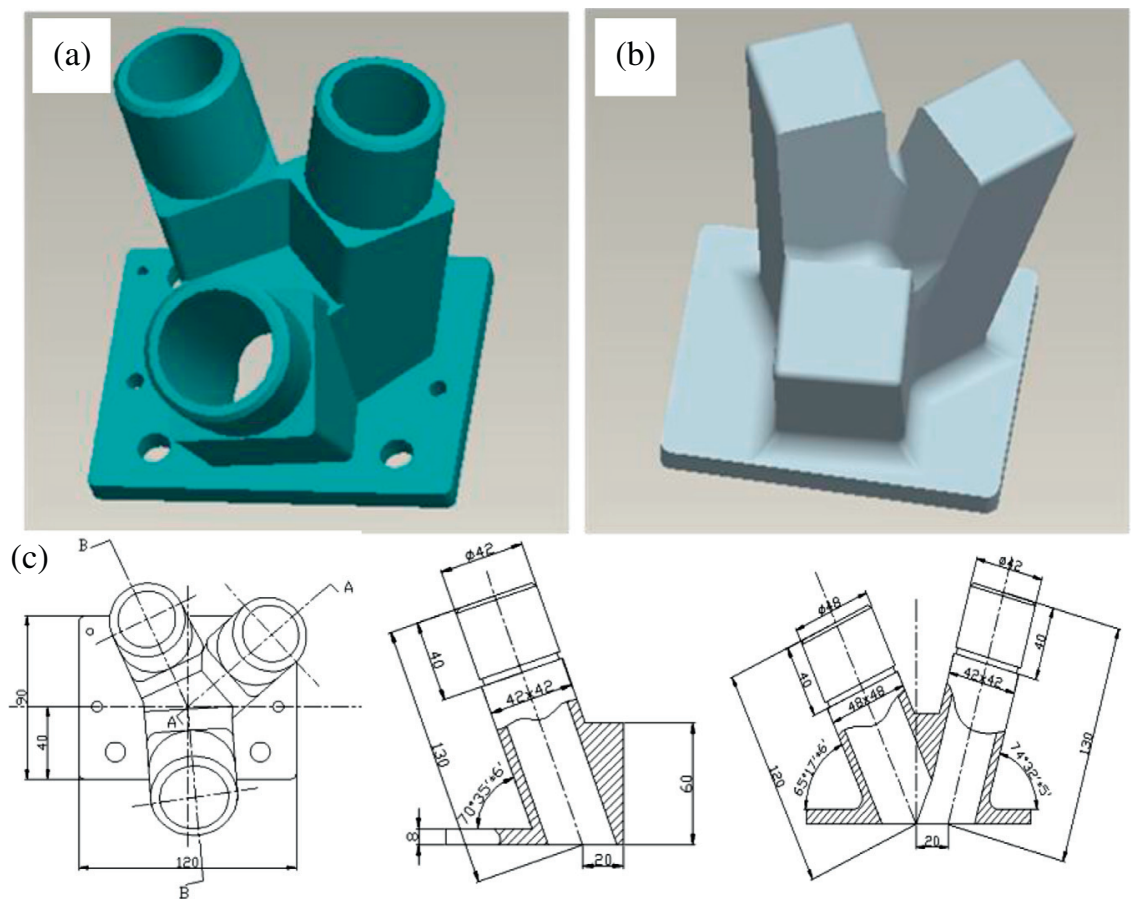

Figure 1. 3D solid modeling drawing of the MB26 magnesium adapter: (a) component, (b) forging billet, (c) 2D dimension of adaptor.

(a)

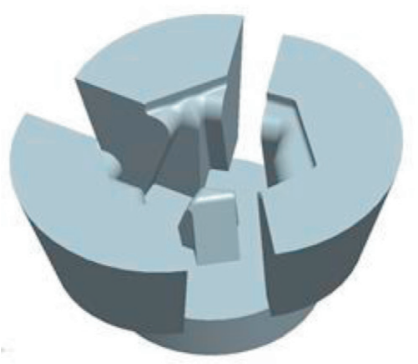

(b)

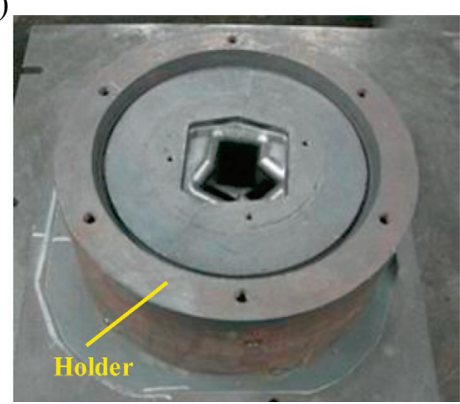

Figure 2. (a) 3D solid modeling drawing of combined die and (b) photo of female die.

(a)

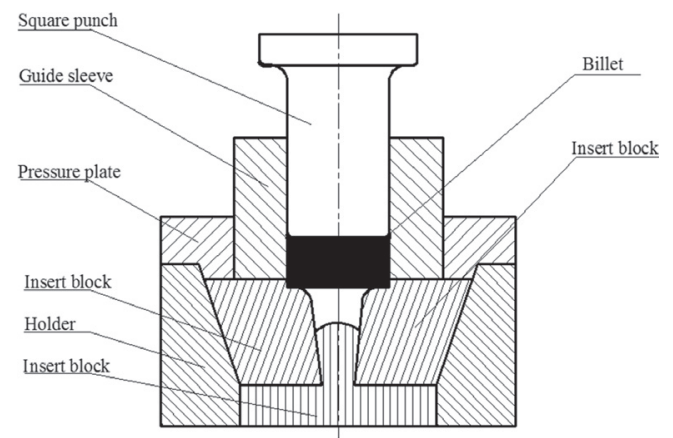

(b)

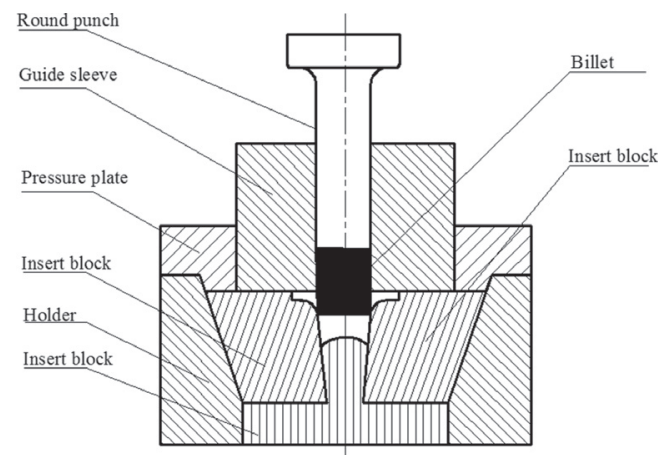

Figure 3. One-step forging scheme. (a) Scheme A, (b) Scheme B. 
(a)

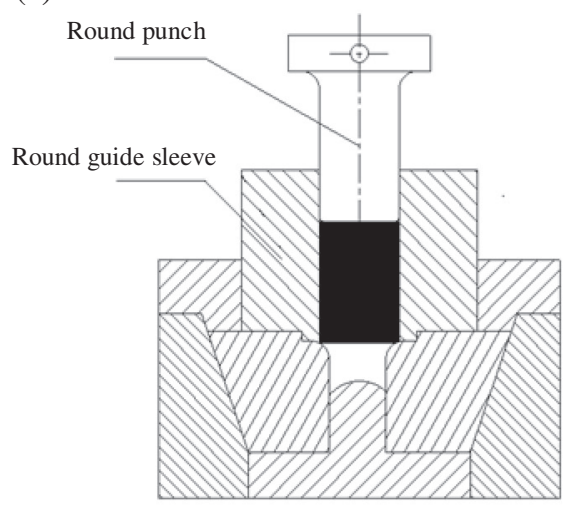

(b)

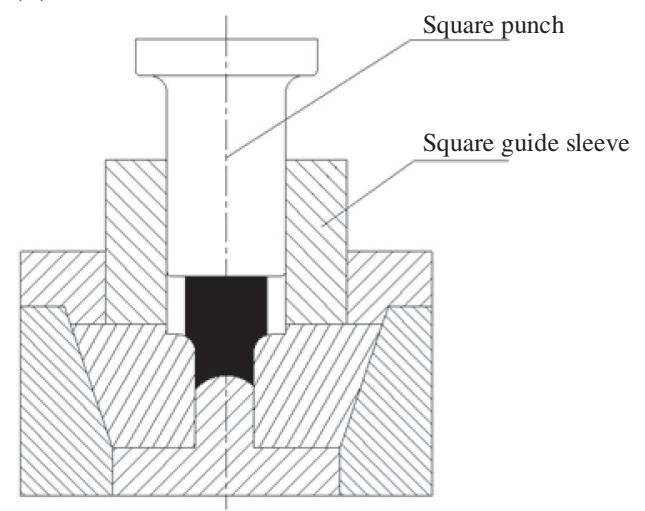

Figure 4. Two-step forging scheme (Scheme C). (a) First step, (b) second step.

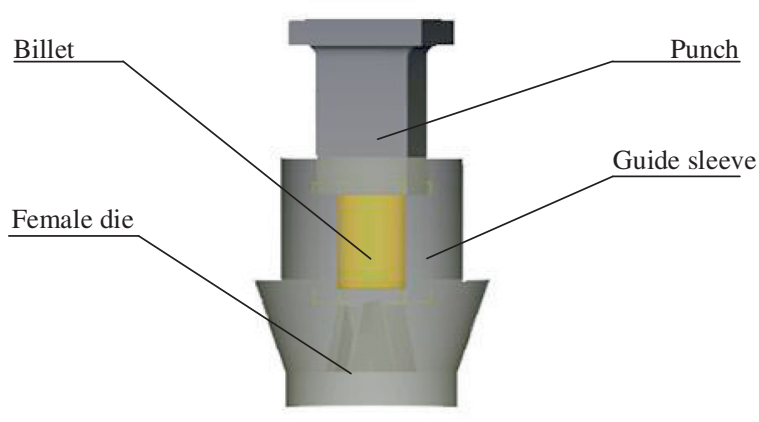

Figure 5. FE model for Scheme A during the forging process. (a)

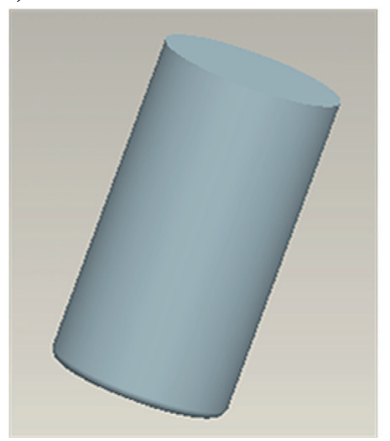

(b)

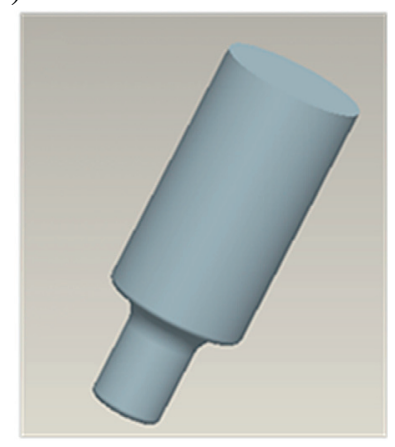

Figure 6. FE models of preform geometries: (a) cylindrical billet, (b) stepped cylindrical billet.

alloy is presented in Table 1. The MB26 magnesium alloy shows excellent mechanical properties and hot workability [13].

Figure 1 shows the 3D solid model of the MB26 magnesium adaptor. As shown in Figure 1a, the MB26 magnesium adaptor consists of a thin web and three branches with a reverse conical angle, and the dimension of adaptor also is shown in Figure 1c. Due to the complex geometry of the adaptor, it is difficult to precisely form the component, so the contour of the adaptor forging is simplified in the consideration of the feasibility of the forging process. The 3D solid

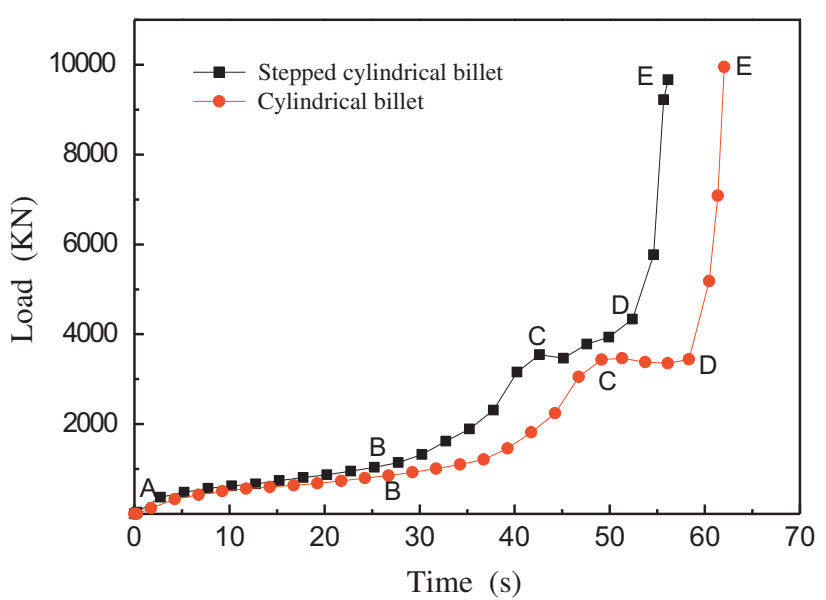

Figure 7. Variation of forging load using forging billet in different shape (A-B: extrusion stage, B-C: upsetting stage, C-D: branch filling stage, D-E: filling of the web and corners of branches stage).

model of the adaptor forging is shown in Figure 1b. All the three branches have rectangular cross sections with the same dimensional size.

\subsection{Design of the split die and forging scheme}

In order to remove the forging from the die after isothermal forging, a set of split female die with vertical parting faces is designed, which is divided into four parts, as shown in Figure 2. In addition, a holder is also used to fix four split parts of die cavity together during the forging process, as illustrated in Figure $2 b$.

To obtain the optimized forging process of the adaptor, three schemes including one-step and two-step forming processes are designed in the study, as shown in Figures 3 and 4. Scheme A and Scheme B belong to one-step process, wherein the punch is rectangular in Scheme A and round in Scheme B, respectively. Scheme C is a two-step forging process, wherein three branches are formed by forward extrusion in the first step and the web is formed by upsetting in the second step. 
(a)

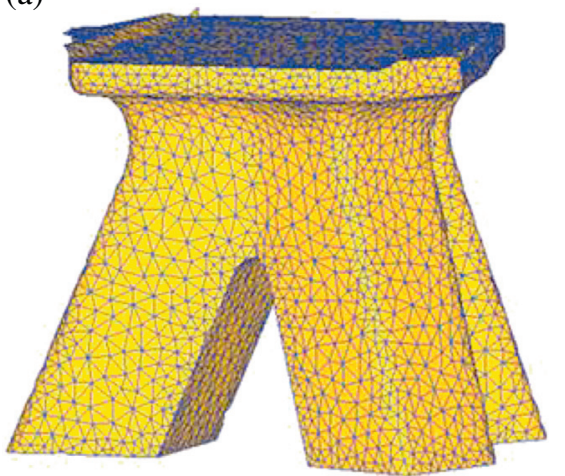

(b)

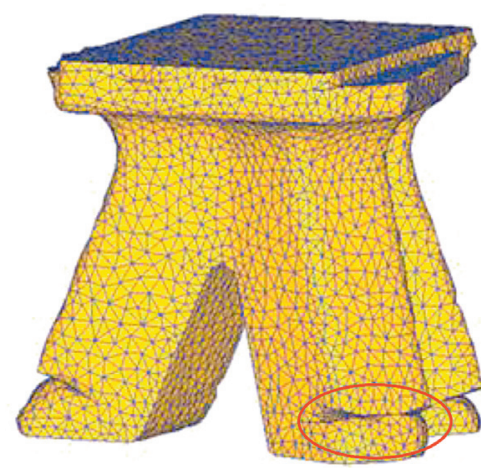

Figure 8. Final geometries of forging adaptors using different billets: (a) cylindrical billet, (b) stepped cylindrical billet.

\section{FE model and experiment conditions}

\subsection{FE model}

Before the isothermal forging experiment, the forging process is simulated so as to understand the laws of metal flow and filling in the die cavity during the forging process, using the $3 \mathrm{D}$ finite element software DEFORM ${ }^{3 \mathrm{D}}$. The material used for FE simulation is MB26 magnesium alloy. However, constitutive relationship of MB26 is not included in the material library of software DEFORM ${ }^{3 \mathrm{D}}$, so the stress-strain relationships under different strain rates [14] were input into the software DEFORM $^{3 \mathrm{D}}$. The constitutive equation of MB26 alloy could be calculated automatically after inputting the measured data.

During the finite element method (FEM) simulation, the speed of the punch is $2 \mathrm{~mm} / \mathrm{s}$. The constant friction factor of 0.3 is selected. The forming process is conducted at an constant temperature of $350{ }^{\circ} \mathrm{C}$. Figure 5 shows the $\mathrm{FE}$ model for Scheme A during the isothermal forging process. The FE models for other schemes are omitted here for the sake of shortening the paper length.

\subsection{Experiment process}

The forging experiment is carried out on a $50,000 \mathrm{KN}$ hydraulic press. The billet and dies are first heated to $100{ }^{\circ} \mathrm{C}$, and then the billet and the dies are lubricated by water-based graphite. Subsequently, they are heated to the working temperature $350{ }^{\circ} \mathrm{C}$. The forging temperature is kept to about $350{ }^{\circ} \mathrm{C}$ in the forging process through on-line resistance heating the combined split die. After the forging process, the adaptor forgings are subject to aging treatment at $165^{\circ} \mathrm{C}$ for $17 \mathrm{~h}$ to improve their mechanical properties. The microstructure is observed by optical microscopy (OM), and the mechanical properties are tested on an Instron 5569 testing machine.

\section{Results and discussion}

Through FE simulation using different billet geometries and forming schemes, the metal flow laws and defect formation mechanisms in the isothermal forging process are (a)

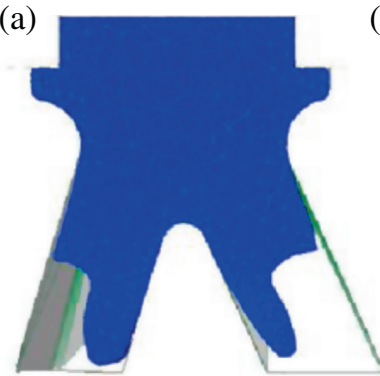

(c)

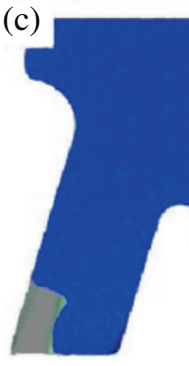

(b)

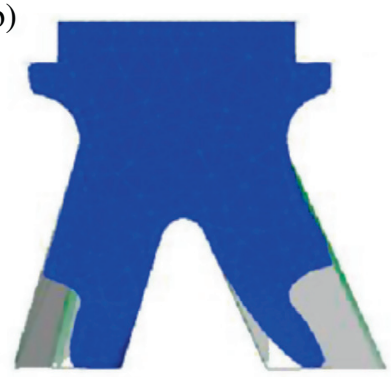

(d)

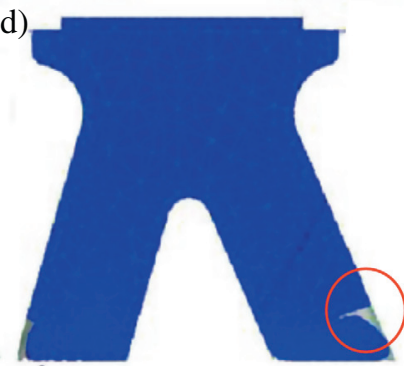

Figure 9. FE results of the forging process using stepped cylindrical billet with total step of 215: (a) 184 step, (b) 195 step, (c) 205 step, (d) 215 step.

analyzed, which are verified by the forging experiments. Afterwards, the optimized forging process is obtained and the adaptor forgings are well formed with good mechanical properties.

\subsection{Preform geometries}

To obtain proper forging preform, different geometries of forging billet are designed, such as cylindrical bar and stepped cylindrical bar, as illustrated in Figure 6 . The cylindrical billet is a cylinder with a diameter in $100 \mathrm{~mm}$, and the stepped cylindrical bar includes two cylindrical sections which are in $100 \mathrm{~mm}$ and $50 \mathrm{~mm}$ respectively. As shown in Figure 3, the female die includes a stepped cavity, so the billet should suffer severe plastic deformation in local area to fill the lower part of stepped cavity. Here, the stepped cylinder billet is designed in order to prefill the lower part of stepped cavity, which may be helpful to fully fill the stepped cavity. Figure 7 shows the 
(a)

(b)

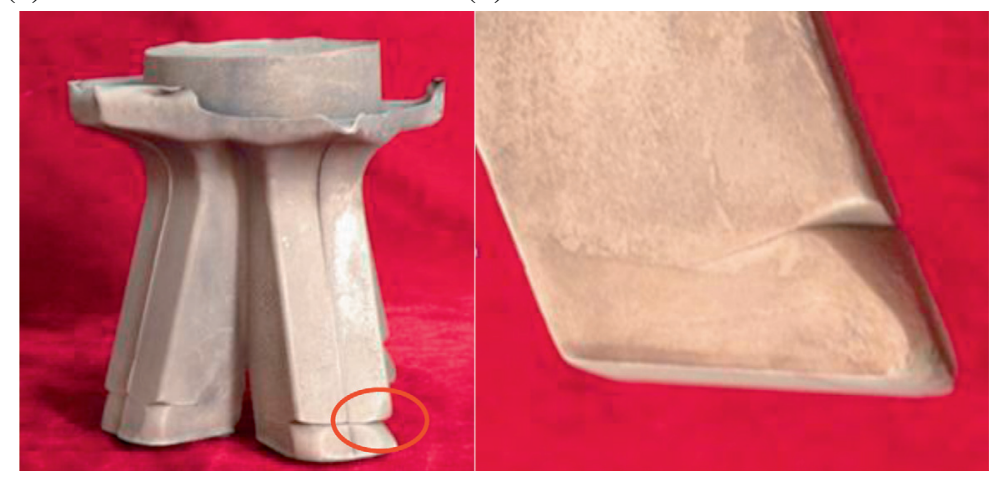

Figure 10. Photographs of fold defect in adaptor forging using the stepped cylindrical billet.

(a)

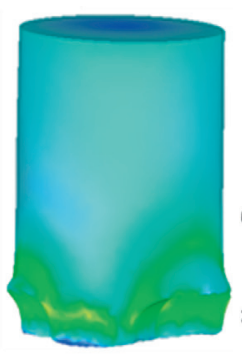

(b)

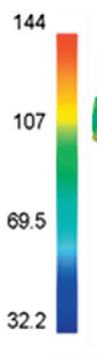

(c)

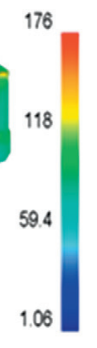

(d)

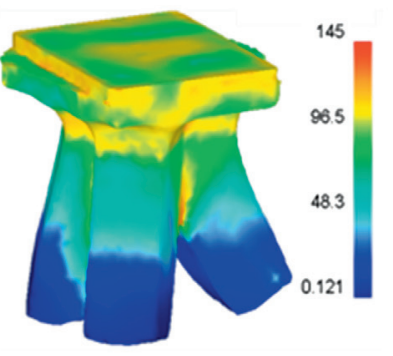

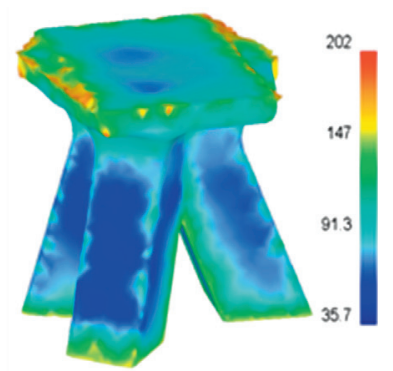

Figure 11. Distribution of equivalent stress at different distances punch travels in Scheme A: (a) $26 \mathrm{~mm}$ (extrusion stage), (b) $96 \mathrm{~mm}$ (upsetting stage), (c) $118 \mathrm{~mm}$ (branch filling stage), (d) $124 \mathrm{~mm}$ (filling of the web and corners of branches stage).

(a)

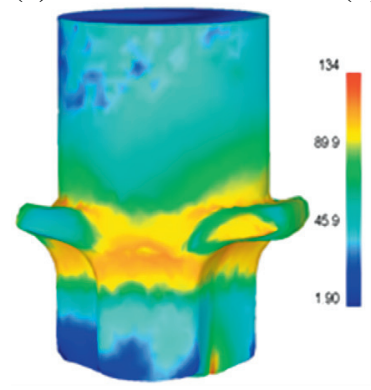

(b)

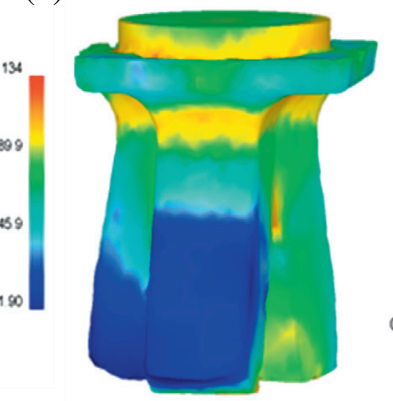

(c)

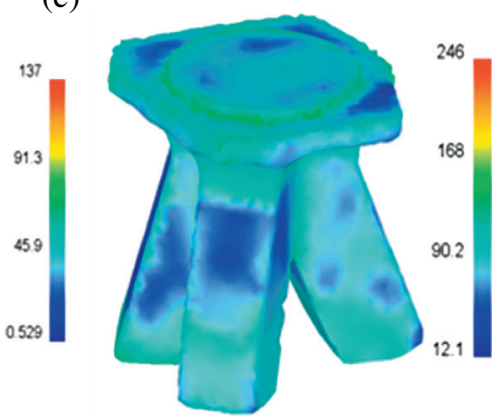

Figure 12. Distribution of equivalent stress at different distances punch travels in Scheme B: (a) $50 \mathrm{~mm}$ (extrusion stage), (b) $110 \mathrm{~mm}$ (branch filling stage), (c) $124 \mathrm{~mm}$ (filling of the web and corners of branches stage).

variation of forging load in the forging process using different forging billets. Both the two forming schemes exhibit similar tendency that the forging load increases slowly at the beginning, followed by rapid increase to a relatively stable stage, and then increases sharply in the final stage. It is because that both the processes experience four similar stages, i.e. extrusion, upsetting, branch filling, filling of the web and corners of branches. The difference between two curves is that the forging load keeps stable by using cylindrical billet in branch filling stage, while it increases slightly by using stepped cylindrical billet in this stage. Actually, the smaller section of stepped cylindrical billet has already entered the female die cavity before extrusion, so the billet quickly contacts the bottom of the female die, subject to a counterforce by the bottom of female die cavity. Because the contact area between the billet and bottom of female die increases gradually, the counterforce applied to the billet increases slowly, resulting in the increase of forging load in the branch filling stage. As for the cylindrical billet, it is split into three branches to fill three passages of the female die cavity at the same speed, and the filling resistance in three passages almost keeps stable before the billet touches the bottom of the female die cavity, producing more stable forging load in the branch filling stage. 


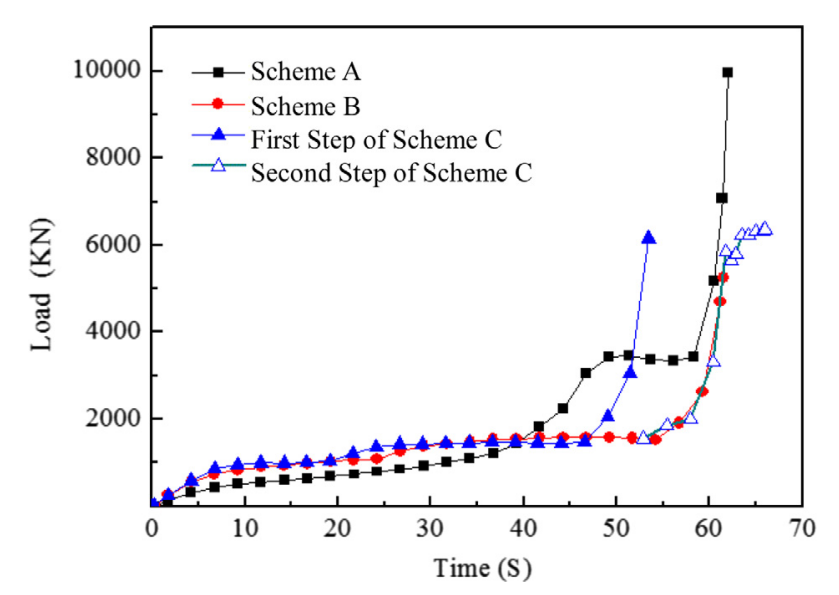

Figure 13. Variation of forging load using different forming schemes in FE simulation.

Figure 8 shows the simulation results of the final shapes of the adaptor forgings using two different initial billets. It can be seen that the folding defect appears on the end of the branches when using stepped billet (Figure $8 \mathrm{~b}$ ), while no folding defect occurs there when using cylindrical billet (Figure 8a). During the forging process, the lower section of the stepped billet has a smaller cross section compared to the upper section, and the lower section of the billet could not fully fill the bottom of the female die cavity, leaving gaps on the bottom of the female die cavity, as indicated in Figures 10a and 10b. In the branch filling stage, the upper section will fill the gaps from the top to bottom of female die, resulting in the formation of folding defects marked with red circle in Figure 9d. In addition, the experimental results of isothermal forging confirm the appearance of folding defect on the branch end marked with red circle, as illustrated in Figure 10. Therefore, the cylindrical billet is more suitable for the forging process compared to the stepped cylindrical one. In the other hand, some defects appearing in the forging experiments can be predicted reliably by the FE simulation results. For example, as shown in Figures 8 and 10, the fold defect appearing on the branch end when using the stepped cylindrical billet in Figure $8 \mathrm{~b}$ is in good agreement with the experiment result in Figure 10. All of the above can give quantitative comparison to validate the FE model.

\subsection{Forging schemes}

Based on the cylindrical billet, three forming schemes are analyzed to determine the proper forging process. Figures 11 and 12 show the FE simulation results of one-step schemes by a square punch and round punch, i.e. Scheme A and B, respectively. Figure 13 shows the load variation during isothermal forging under various forming schemes. During the forging process, the punch presses the billet downwards at a speed of $2 \mathrm{~mm} / \mathrm{s}$ in total time of $65 \mathrm{~s}$, moving a total distance of $124 \mathrm{~mm}$ along the height direction. As mentioned above, the three stages consisting of extrusion, branch filling, web filling appear both in Scheme A and B. In the extrusion stage, the punch compresses the billet into the top opening above

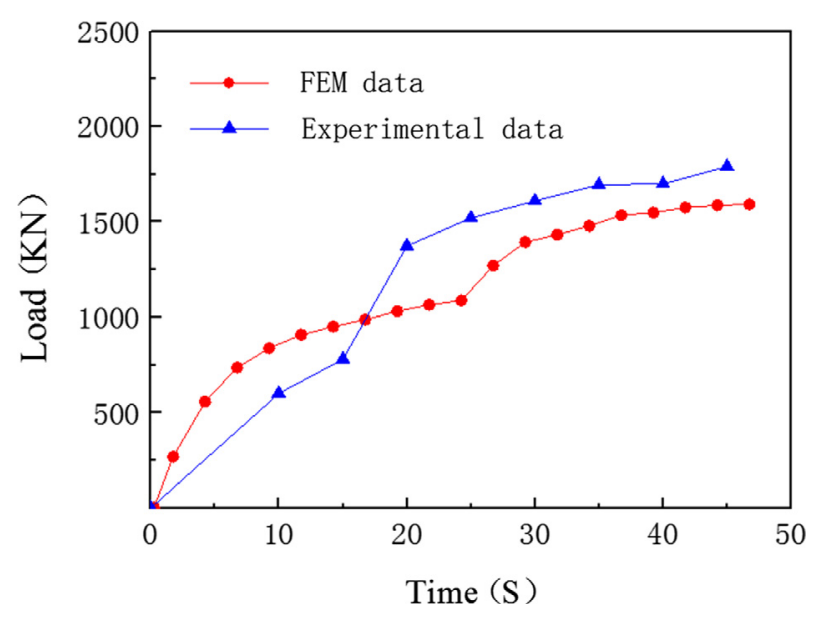

Figure 14. The evolution of forging load in one-step scheme using cylindrical billet and round punch.

(a)

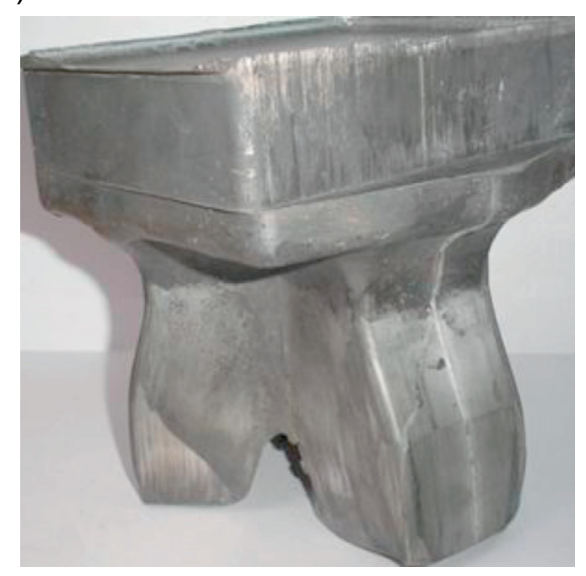

(b)

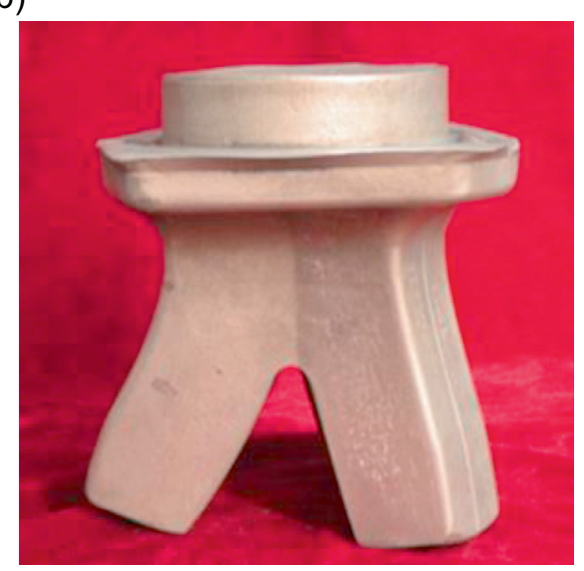

Figure 15. Underfilling defect of the adaptor forging under different schemes: (a) Scheme A, (b) Scheme B.

three branches. In the branch filling stage, the metal flows into three passages until touching the bottom of the female die cavity. In the web filling stage, the top of the billet is upset and the corner cavity is filled as fully as possible. But the upsetting deformation takes place simultaneously on the top 
(a)

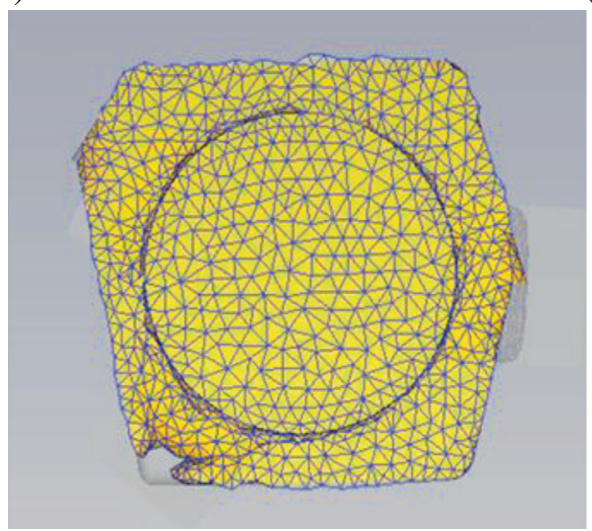

(b)

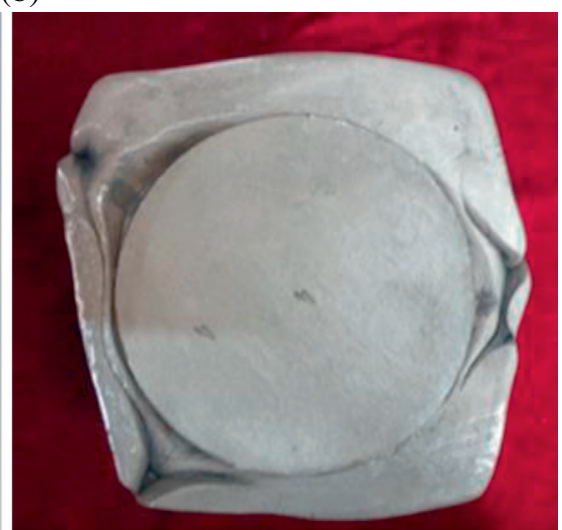

Figure 16. Folding defect of the billet in Scheme B: (a) FE simulation result, (b) experimental photo.

(a)

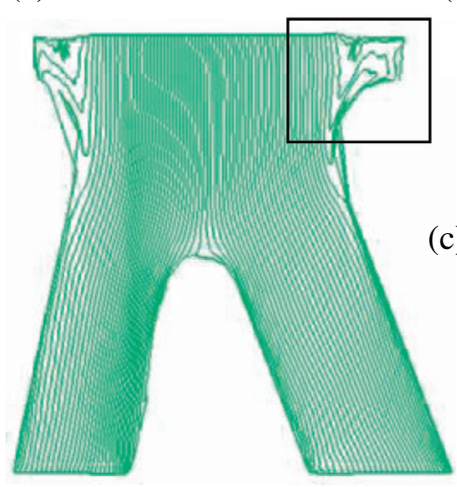

(b)

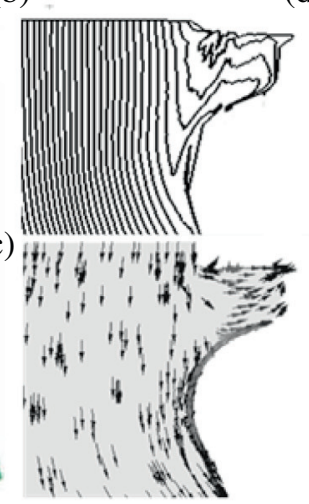

(d)

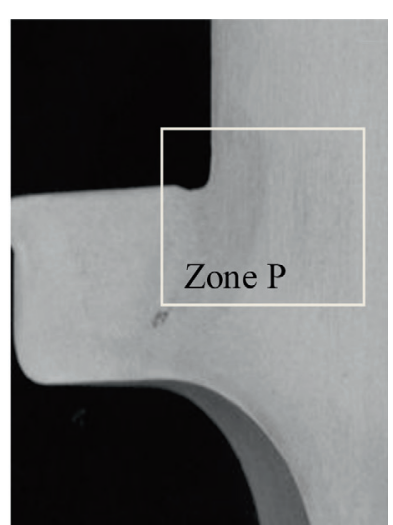

Figure 17. Flow line distribution of the adaptor forging in Scheme B: (a) flow distribution, (b) flow distribution in the web, (c) flow velocity distribution in the web, (d) experimental photo.

of the cylindrical billet in the extrusion stage of Scheme A. In addition, the maximum load under Scheme $\mathrm{A}$ is much greater than under Scheme B, as illustrated in Figure 13. The cross section dimension of the rectangle punch is bigger than that of the top opening above three branches bordering the web in Scheme A, so the forging force exerted on the web may be counteracted by the combined female die, increasing the filling resistance, while the cross section area of the round punch is nearly the same to the corresponding opening in Scheme B, reducing the filling resistance. Also, it can be found that in the web filling stage, the high stress zone is distributed on the whole web (Figure 11c) in Scheme A, while it localizes to the center of the web in Scheme B (Figure 12c). Due to the large flow resistance in the final filling stage, the forging load sharply increases from $4000 \mathrm{KN}$ to $10,000 \mathrm{KN}$ in Scheme A, which is much greater than that in Scheme B (Figure 13).

In fact, the forging load in the forging experiment of cylindrical billet using one-step scheme by a round punch is measured in the early $45 \mathrm{~s}$, and the experimental data is compared with FEM data, as shown in Figure 14. It can be seen from Figure 14 that the evolution of forging load in the forging experiment is basically consistent with the FE simulation. (a)

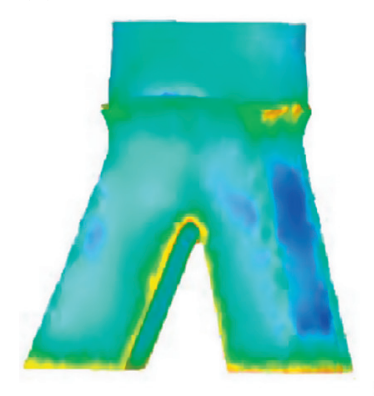

(b)

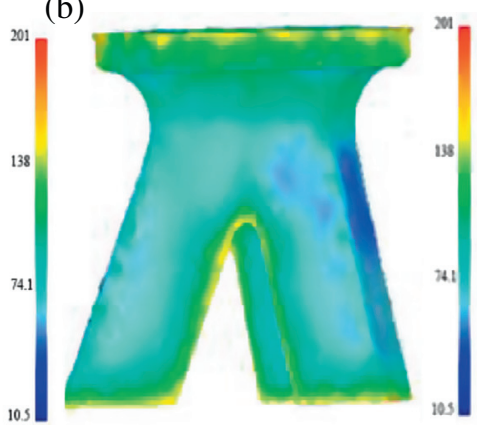

Figure 18. Distribution of equivalent stress at different distances punch travels in Scheme C: (a) end of the first step, (b) end of the second step.

However, both Scheme A and Scheme B are not able to form good adaptor forgings since some defects appear during the forging process. The underfilling is a common defect occurring both in Scheme A and B, as shown in Figure 15. In forging practice, the metal subjected to the compression of the punch is split into three branches in the three passages 
(a)

(b)

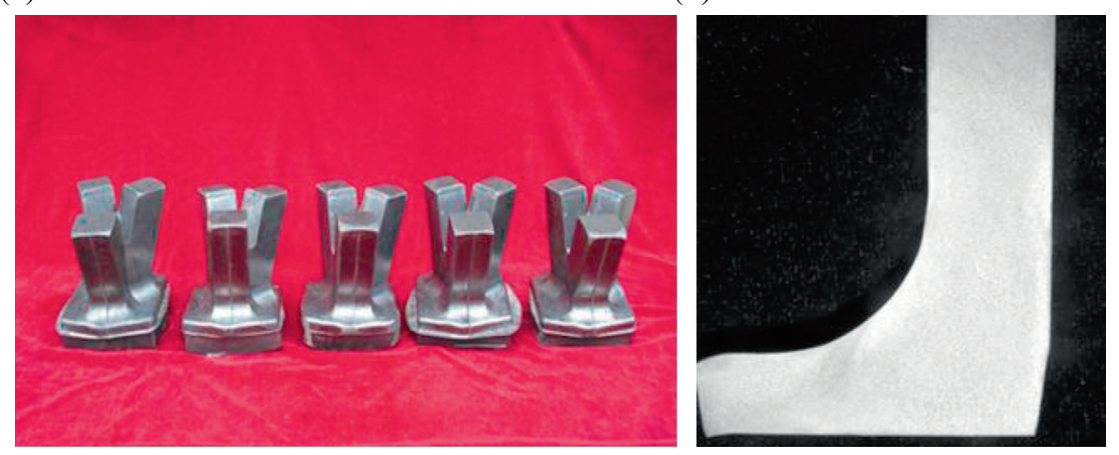

Figure 19. Photographs of adapter forgings using two molding scheme: (a) final components, (b) macrostructure of web area.

of female die cavity, where the filling resistance is very large due to the reversed cone angle of three branches. Even though high punch pressure is exerted on the billet, it is counteracted by the filling resistance, increasing the difficulty in filling the die cavity of three branches. As can be seen in Figures 12 and 13, the stresses of the bottom of three branches are very low compared to that of the web on the branches, which indicates that the plastic deformation mainly produces in the vicinity of the web and it is very hard to force the metal flow to the bottom of three branches of the female die albeit with high forging load.

Although the underfilling defect is not so evident in Scheme B, the overlap as well as flow-line turbulence appears on the web, as shown in Figures 16 and 17. In Scheme B, the cross section of round punch is much smaller than the area of web, so the metal of billet flows radially into the web cavity in the web filling process. The metal contacts the side wall of the web cavity earlier because the distance from the punch to the side wall of the web cavity is shorter than that from the punch to the corners of the web cavity. Thus the metals from adjacent two side walls close to the corner will flow towards the corners to meet there together, leading to the formation of the folding defect. In addition, the flow line on the web is turbulent in that the web and three branches of the adaptor forging are formed almost simultaneously, so the metal of the transitional zone between the web and the branch flowing into the web cavity earlier could be partly dragged out toward the branch cavity, leading to the formation of turbulent flow line at Zone P in Figure 17d.

To avoid forging defects of the adaptor forging, Scheme C is designed in the present study. This scheme is divided into two steps, wherein three branches are formed by forward extrusion in the first step and the web is formed by upsetting in the second step. The round punch is employed in the first step to improve filling degree of the female die cavity and reduce the stress exerted on the top opening of female die. And the square punch which has bigger cross section is employed in the second step to avoid the folding defect on the web. The two-step scheme combines the flow characteristics of the Scheme A and Scheme B, and both the simulation and experimental results indicate that the adaptor forgings could be well formed without forging defects, as shown in Figures 18 and 19, respectively. Figure 18 shows relative low stress and good filling performance during the simulation process of Scheme C compared to Scheme A and B. Moreover, no turbulence of flow line is observed on the transitional zone between the web and the branch (Figure 18b). Additionally, the forging load in each step is relatively low, which is close to that in Scheme B, as shown in Figure 13. Therefore, the two-step scheme is a proper process to produce the adaptor forging, which is better for improving forging quality, saving energy and ensuring the die life.

\subsection{Microstructure evolution and mechanical properties}

Figure 20 shows the optical microstructures of the adaptor forgings using Scheme $\mathrm{C}$ at various positions. It can be seen that the fine extruded microstructure remains in the branch with fiber-like morphology. Different from the microstructure in the branches, the microstructure in the web exhibits obvious orientation rearrangement, as shown in Figure 20c. It is because that severe compression deformation appears to form the web of the adaptor forging. During the forging process, the upsetting deformation in the second step causes the metal to flow radially, which is perpendicular to the extruded fiber-like microstructure, so the fiber-like structures are kinked and broken, which indicates the rearrangement of the orientation of fiber-like structure. The severe plastic deformation appears to form the web of the adaptor forging, resulting in evident grain refinement in the web.

In order to improve mechanical properties, aging treatment is applied to the forging adaptor at $165^{\circ} \mathrm{C}$ for $17 \mathrm{~h}$. The tension tests show that yield strength and tensile strength of forging adaptor slightly increase from $226 \mathrm{MPa}$ to 244.5 MPa and from $300 \mathrm{MPa}$ to $304.7 \mathrm{MPa}$, respectively. Meanwhile, the elongation increases from $15 \%$ to $18.2 \%$. The microstructures of the web zone in the forging adaptor before and after aging treatment are compared, as shown in Figure 21. It indicates that the precipitation slightly increases within the grains after aging treatment without obvious change of grain morphology, which could improve the strength of the forging adaptor. The enhancement of the elongation should be related to the specific precipitation of Mg-RE (rare earth) phase during the ageing treatment, which needs further study in the future. 
(a)
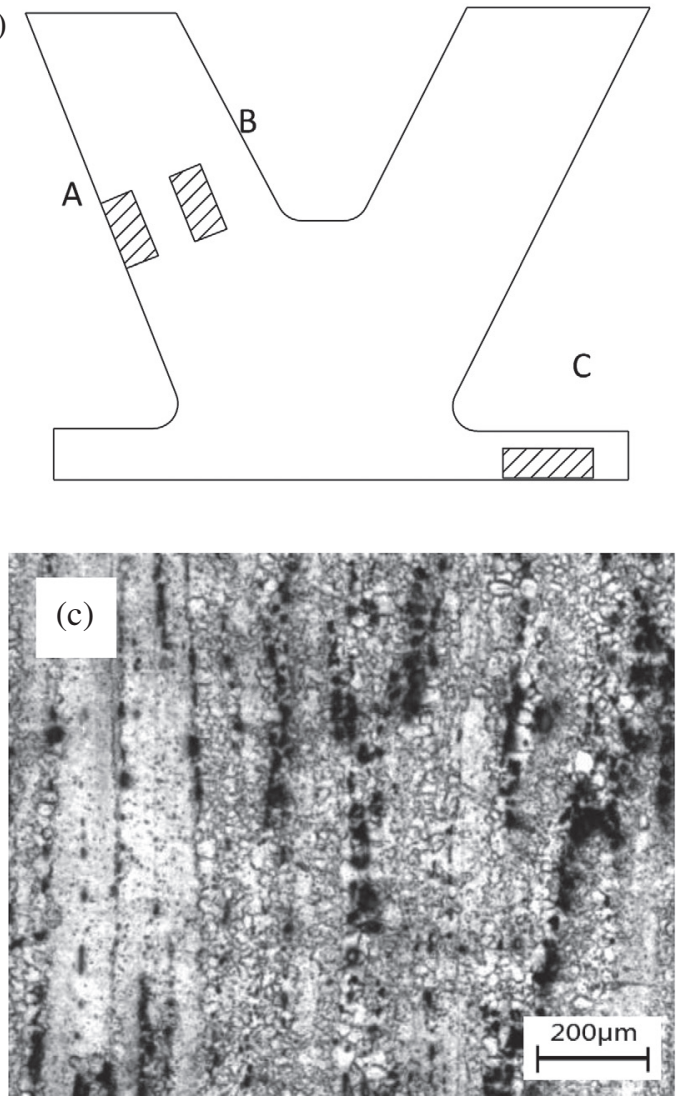
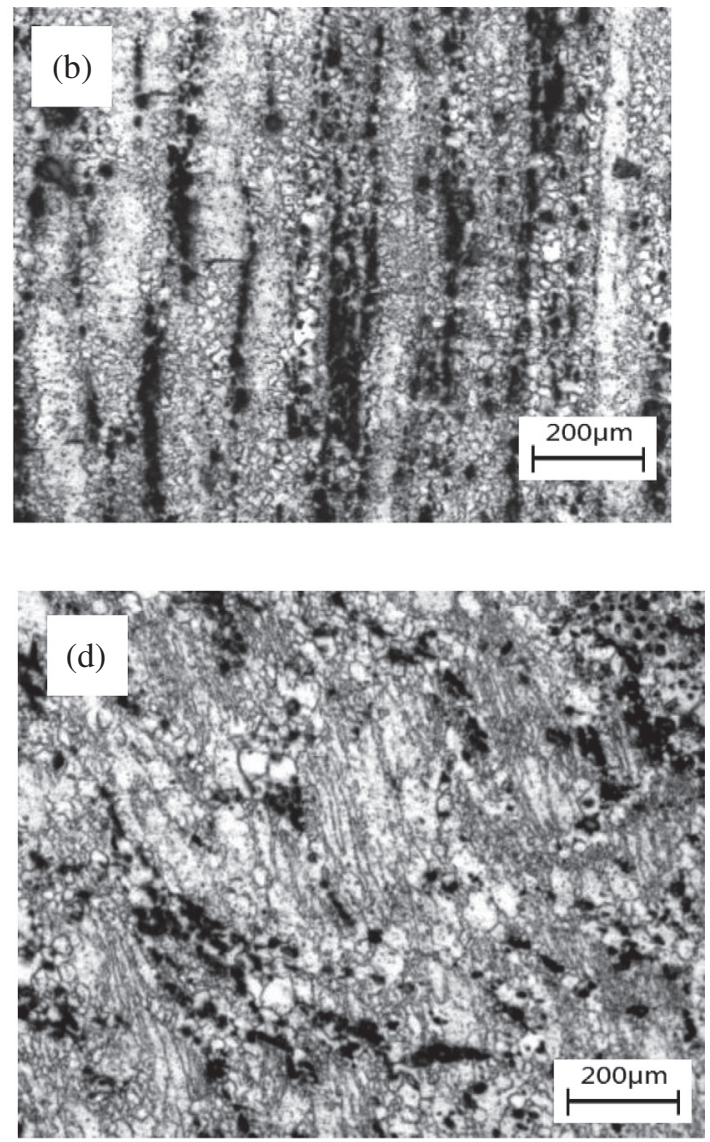

Figure 20. Optical microstructures on different locations of adaptor forging: (a) sampling positions of forging for microstructure observation, (b) surface zone of the branch (Zone A), (c) inner zone of the branch (Zone B), (d) web zone (Zone C).
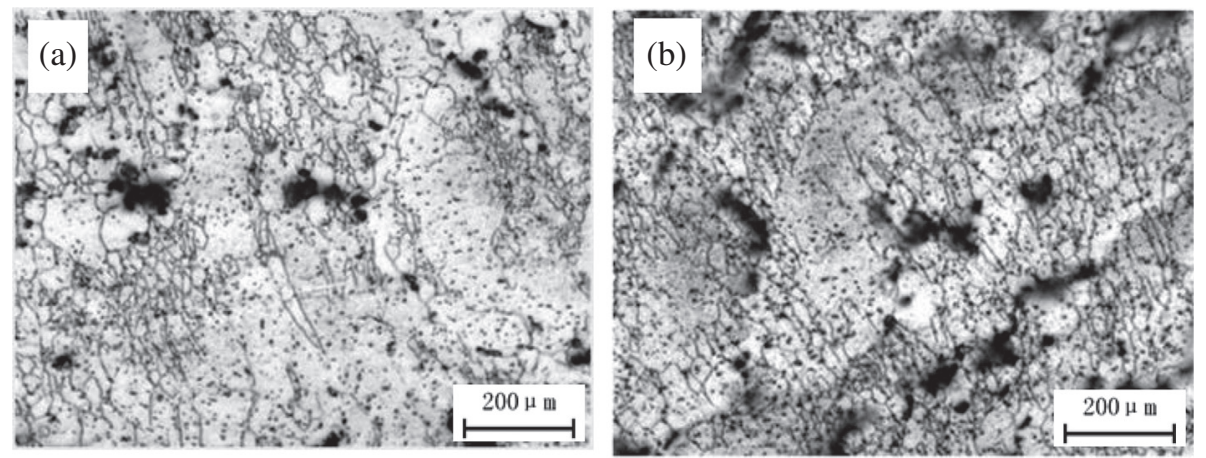

Figure 21. Metallographs of web area in forging adaptor: (a) before aging treatment, (b) after aging treatment.

\section{Conclusions}

Based on the FEM simulations and forging experiments, the forging process scheme for the forming of the MB26 alloy adaptor with three branches was designed and optimized, and the microstructure and mechanical properties were analyzed. The main conclusions are drawn as follows:

1. The combined female dies could be separated along the longitudinal direction of the adaptor forging, and hence, the complex adaptor with three branches could be removed from the die cavities easily.

2. The billet geometry and forming scheme have important influences on the forming quality of the adaptor forging. The folding defect appeared when using a stepped cylindrical billet, while no folding defect occurred when using a cylindrical billet. The underfilling is a common defect appearing in one-step schemes, including Scheme A and B, and the overlap and the flow-line turbulence occurred in the web in the Scheme B. In the 
two-step scheme (Scheme C), not only the forming defect could be avoided, but also the forging load was reduced greatly. In addition, the flow line was uniformly distributed along the contour of the adaptor forging. Therefore, the cylindrical billet and the two-step forging scheme are approved to be better for forming the adaptor forging.

3. In the forging of the adaptor, the fiber-like extruded morphology remained in the branch, while obvious grain refinement and grain orientation change took place in the microstructure of the web section.

4. The aging treatment could induce small increase of precipitates within the grains without changing grain morphology evidently, slightly improving the mechanical properties of the adaptor forging.

\section{References}

1. H.J. Zhang, J. Meng, D.X. Tang, J. Chin. Rare Earth Soc. 22 (2004) 40-47.

2. Y.Y. Li, W.W. Zhang, Y. Liu, W.P. Chen, D.H. Ni, Spec. Casting \& Nonferrous Alloys 1 (2004) 14-17.
3. Y.M. Hu, H. Xie, Z.F. Sun, Plast. Working Technol. 39 (2004) 5.

4. R. Kopp, J. Mater. Process. Technol 60 (1996) 1-10.

5. Y.H. Qu, J.K. Sun, X.J. Meng, Tit. Ind. Prog. 23 (2006) 6-9.

6. M.G. Yan, Hot Working Technol. 3 (2003) 26-28.

7. J.P. Fuertes, C.J. Luis, R. Luri, D. Salcedo, J. León, I. Puertas, J. Manuf. Processes 21 (2016) 56-68.

8. Y.Q. Zhang, S.Y. Jiang, Y.N. Zhao, D.B. Shan, Mater. Sci. Eng: A 580 (2013) 294-304.

9. Y. Lu, F.C. Xu, K.M. Xue, D.B. Shan, Z. Wang, Y. Xu, X.Y. Kong, Y.Z. Zhao, N.H. Hao, J. Har. Ins. Tech. 32 (2000) 127-129.

10. A. Dziubińska, A. Gontarz, K. Horzelska, P. Pieśko, Procedia Manuf. 2 (2015) 337-341.

11. A.S. Rabori, A.Z. Hanzaki, S.M. Fatemi, M. Ghambari, M. Moghaddam, J. Alloys Compd. 693 (2017) 406-413.

12. H.L. He, S.Q. Huang, Y.P. Yi, W.F. Guo, J. Mater. Process. Technol. 246 (2017) 198-204.

13. H.J. Zhang, J. Meng, D.X. Tang, J. Chin. Rare. Earth. Soc. 22 (2004) 40-47.

14. Z.H. Du, X.H. Zhang, X.Y. Fang, X.J. Zhang, Y.L. Chen, Y.W. Zhang, Trans. Nonferrous Met. Soc. China 17 (2007) 400-404.

Cite this article as: $\mathrm{Xu} \mathrm{W}$, Yang $\mathrm{C}$, Shan $\mathrm{D} \&$ Guo B: Process design based on FE simulations and experiments of forging a complexshaped magnesium alloy adaptor. Manufacturing Rev. 2017, 4, 9. 